
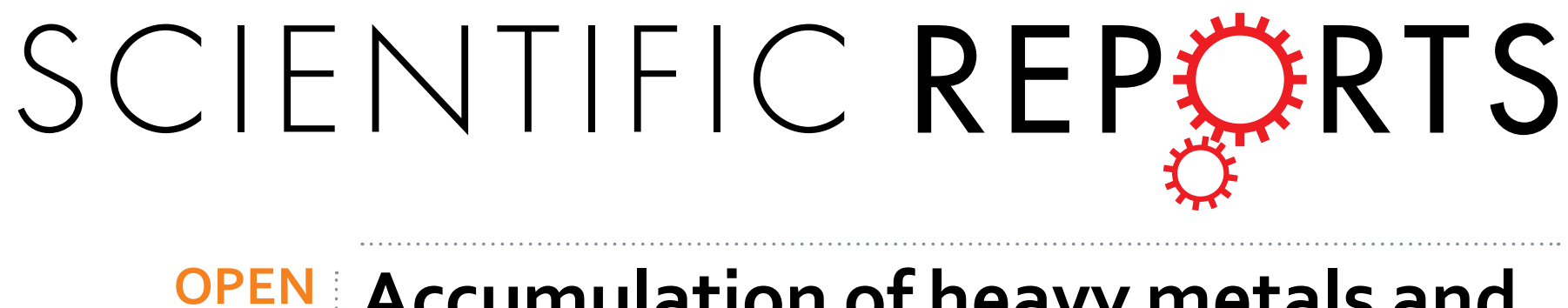

\title{
Accumulation of heavy metals and trace elements in fluvial sediments received effluents from traditional and semiconductor industries
}

Received: 02 April 2016

Liang-Ching Hsu ${ }^{1}$, Ching-Yi Huang ${ }^{2}$, Yen-Hsun Chuang ${ }^{2}$, Ho-Wen Chen ${ }^{2}$, Ya-Ting Chan $^{3}$,
HengYi Teah ${ }^{4}$, Tsan-Yao Chen ${ }^{5}$, Chiung-Fen Chang ${ }^{2}$, Yu-Ting Liu ${ }^{3} \&$ Yu-Min Tzou

Metal accumulation in sediments threatens adjacent ecosystems due to the potential of metal mobilization and the subsequent uptake into food webs. Here, contents of heavy metals $(\mathrm{Cd}, \mathrm{Cr}, \mathrm{Cu}, \mathrm{Ni}$, $\mathrm{Pb}$, and $\mathrm{Zn}$ ) and trace elements ( $\mathrm{Ga}, \mathrm{In}, \mathrm{Mo}$, and $\mathrm{Se}$ ) were determined for river waters and bed sediments that received sewage discharged from traditional and semiconductor industries. We used principal component analysis (PCA) to determine the metal distribution in relation to environmental factors such as $\mathrm{pH}, \mathrm{EC}$, and organic matter (OM) contents in the river basin. While water PCA categorized discharged metals into three groups that implied potential origins of contamination, sediment PCA only indicated a correlation between metal accumulation and OM contents. Such discrepancy in metal distribution between river water and bed sediment highlighted the significance of physical-chemical properties of sediment, especially OM, in metal retention. Moreover, we used Se XANES as an example to test the species transformation during metal transportation from effluent outlets to bed sediments and found a portion of Se inventory shifted from less soluble elemental Se to the high soluble and toxic selenite and selenate. The consideration of environmental factors is required to develop pollution managements and assess environmental risks for bed sediments.

Heavy metal distribution has been one of the critical concerns in natural environments due to their toxicity and biomagnification attributes. Lots of regulations have been established to avoid heavy metal concentrations in waters, sediments, and soils exceed quality criteria for environmental protection. Anthropogenic activities have discharged significant amounts of heavy metals into rivers. By accumulated in sediments, heavy metals could enter the food chain as bottom sediments in river basin or reservoirs serve as habitats and food sources for benthic fauna. Subsequently, heavy metals may directly or indirectly threaten the aquatic flora and fauna. Thereby, metal contamination in sediments has been an ongoing issue worldwide ${ }^{1}$ as sediment-bound metals may be of great significance for water quality and ecosystem health ${ }^{2,3}$.

According to chemical and geological conditions, heavy metals discharged into surface waters were rapidly partitioned onto particulate matter and incorporated in sediments. Based on the matrix composition, sediments generally show a superior capacity for metal retention ${ }^{4}$. The degree of heavy metals and trace elements retained in sediments is controlled by not only the dynamics of physical-chemical equilibration, which is governed by $\mathrm{pH}$, redox conditions, oxidation states of elements, etc., but also sediment attributes such as particle size and contents for organic matter (OM) as well as Fe/Mn (hydr)oxdies ${ }^{5}$. Most importantly, the relative abundance of heavy metals in sediments is mainly dependent on the waste discharged from industrial and other anthropogenic activities $^{6,7}$. 


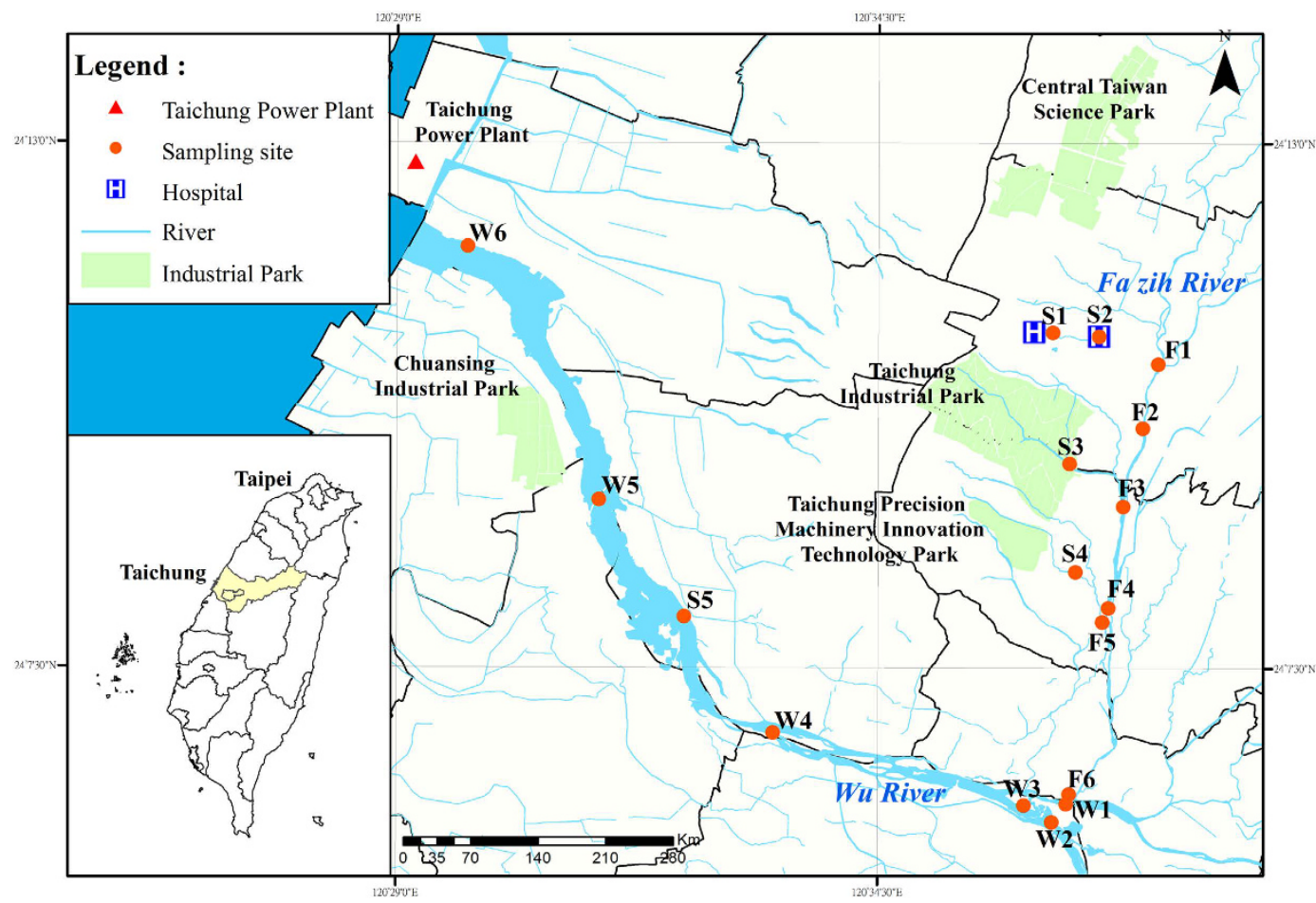

Figure 1. Sampling sites for river waters, sediments, or discharged sewage effluents in the Fazih and the Wu River basin. Water and sediment samples were collected from 12 sampling sites scattered in the Fazih River (F1-F6) and the Wu River (W1-W6). The sewage effluents were discharged from hospitals (S1 and S2), the Taichung Industrial Park (S3), the Taichung Precision Machinery Innovation Technology Park (S4), and the Central Taiwan Science Park (S5). The map was generated using ArcGIS 10.0 software.

Our study site locates at the basin of the Fazih and the Wu River in Taichung, Taiwan (Fig. 1). This basin has received treated wastewater from the Taichung Industrial Park, the Taichung Precision Machinery Innovation Technology Park, the Central Taiwan Science Park, and untreated wastewater from domestic original equipment manufacturers (OEM). More than 19 million tons of wastewater has been discharged annually into the Fazih and the $\mathrm{Wu}$ River. Amounts and types of metals discharged may vary according to sources and intensities of industrial activities. For traditional industrial activities such as printed board manufacturing, metal finishing and electroplating, and textile dyes, the discharged heavy metals generally consist of cadmium (Cd), chromium (Cr), copper $(\mathrm{Cu})$, nickel $(\mathrm{Ni})$, lead $(\mathrm{Pb})$, zinc $(\mathrm{Zn})^{6,8-12}$, etc. For the semiconductor industries, however, the intensive development of manufacturing processes has embraced a boom in the application of trace elements such as selenium (Se), gallium (Ga), indium (In), and molybdenum (Mo) to improve the performance of thin film growth, chemical polishing, and photolithography.

Here, we aimed to determine how environmental factors such as $\mathrm{pH}$, electrical conductivity (EC), oxidation-reduction potential (ORP), OM, amorphous (oxalate-extractable) aluminum (Al) and (Fe) dominate the accumulation of heavy metals and trace elements in bed sediments. Data sets on environmental factors and metal contents in river water and bed sediments were subjected to principal component analysis (PCA) to ascertain factors that were responsible for the variation in metal loading in sediments. In particular, Se speciation was performed as an example to examine the species transformation in relation to environmental changes by $\mathrm{X}$-ray absorption near edge structure (XANES) analysis during the transportation from effluent outlet to bed sediments. Recognition of the metal enrichment factors could lead to a better estimation of the dynamics and mass balance of heavy metals and trace elements in contaminated sediments and thereby an improved strategy for wastewater discharge management.

\section{Results}

Environmental parameters. Our study sites locate at the basin of the Fazih and the Wu River in Taichung, Taiwan (Fig. 1). This $26-\mathrm{km}$ basin has contained wastewater discharged from hospitals, the Taichung Industrial Park (traditional industrial activities), and the Central Taiwan Science Park (semiconductor industrial activities). Therefore, possible pollutants in this basin consist of emerging contaminants, heavy metals, and trace elements. The mean $\mathrm{pH}$ of individual sampling sites ranged from 6.5 to 7.5 (Fig. 2a). There was no significant variation in $\mathrm{pH}$ among all samples. Similar trend was found in the ORP (Fig. 2b). With the exception of the S2 sample, whose mean ORP is $-55 \mathrm{mV}$, the mean ORP for other samples ranged from 134 to $235 \mathrm{mV}$. Coupled with the neutral $\mathrm{pH}$ level, the redox potential for all samples but S2 lay in the sub-oxic status, implying the redox potential was low enough to deplete $\mathrm{O}_{2}$ but not reduced $\mathrm{SO}_{4}{ }^{13}$. On the contrary, $\mathrm{S} 2$ was in an anoxic condition, wherein the redox potential was low enough to deplete $\mathrm{SO}_{4}$. For the EC, the sewage effluent samples (S1-S5) generally showed the 

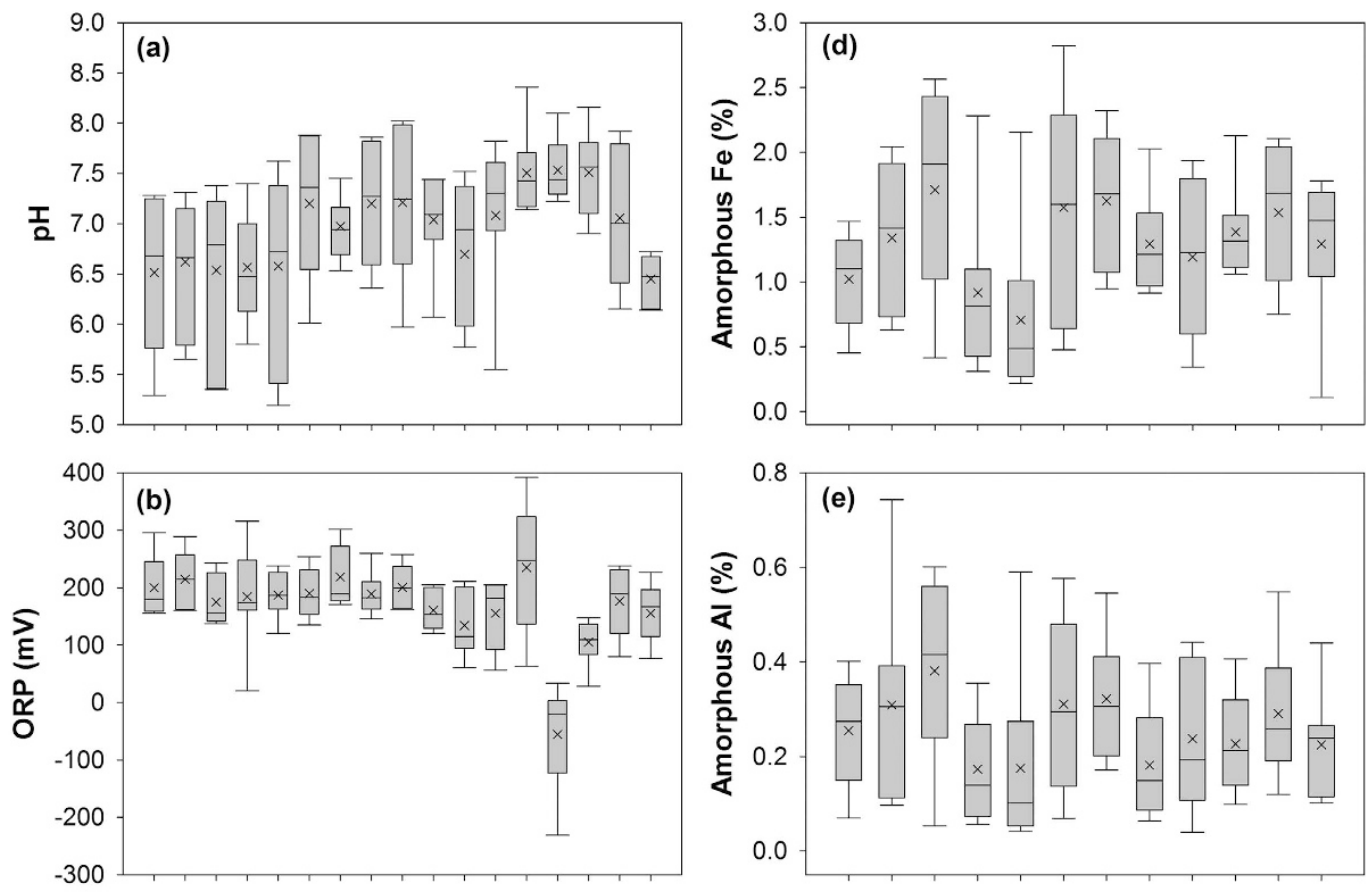

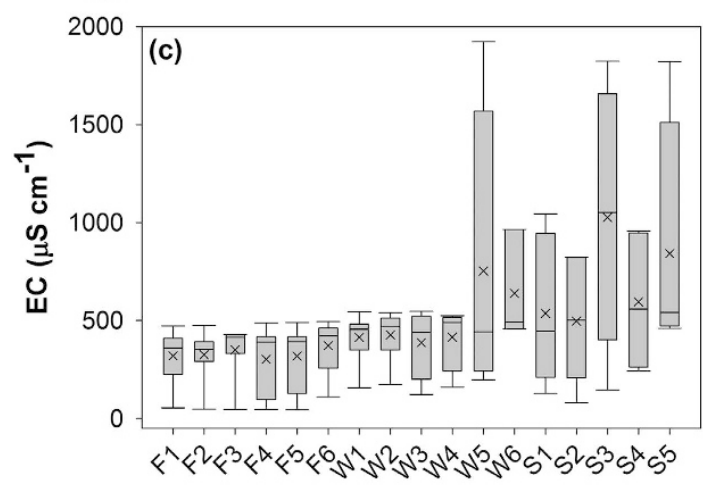

Sampling sites

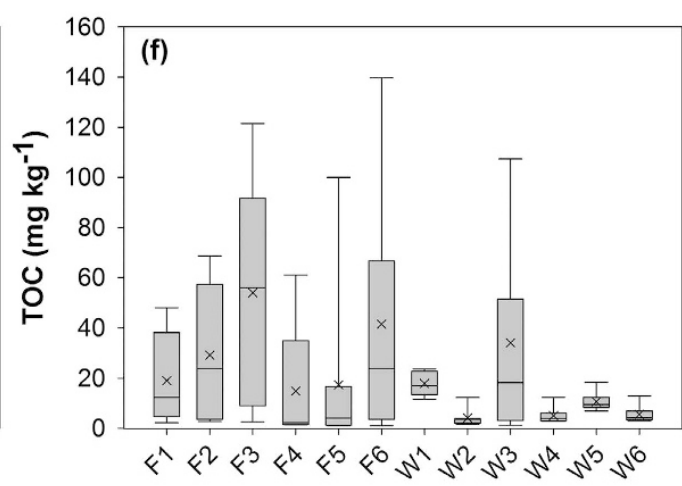

Sample sites

Figure 2. Environmental factors of water. (a) pH, (b) ORP, and sediments (c) EC, (d) amorphous Fe, (e) amorphous Al, and (f) TOC for the sampling sites. The $\mathrm{pH}$, ORP, and EC data were collected from water samples. Amount of amorphous $\mathrm{Fe}, \mathrm{Al}$, and TOC were derived from sediment samples.

relatively higher EC than that of the Fazih River (F1-F6) and most of the Wu River (W1-W4) samples (Fig. 2c). The mean EC for the sewage effluent samples ranged from 497 to $842 \mu \mathrm{S} \mathrm{cm}^{-1}$, resulting in a significant increase in EC for water samples collected at lower reaches of such effluents (W5 and W6). The enhancement in EC for the W6 sample might be also caused by the seawater intrusion as the sampling site of W6 locates close to the river mough.

Regarding chemical parameters of solid phases, we determined the contents of TOC and amorphous Fe and $\mathrm{Al}$ in sediments. For the amorphous (oxalate-extractable) $\mathrm{Fe}$ (0.71 to $1.71 \%)$ and $\mathrm{Al}(0.17$ to $0.38 \%$ ), no particular pattern could be identified according to the sampling geographical locations (Fig. 2d,e). However, TOC contents in sediments seemed to be divided into two groups associated with individual river basins (Fig. 2f). While the mean TOC contents for most sediment samples ranged from 15 to $54 \mathrm{mg} \mathrm{kg}^{-1}$, that for W2, W4, W5, and W6 sediments were less than $10 \mathrm{mg} \mathrm{kg}^{-1}$.

Heavy metals and trace elements in river waters and sewage effluents. Figure 3 showed the maximum, mean, median, and minimum concentrations for $\mathrm{Cd}, \mathrm{Cr}, \mathrm{Cu}, \mathrm{Ni}, \mathrm{Pb}, \mathrm{Zn}, \mathrm{Ga}, \mathrm{In}, \mathrm{Mo}$, and $\mathrm{Se}$ in river waters and sewage effluents. Metal concentrations were compared with the criterion continuous concentrations (CCC - dash lines in Fig. 3) established by the U.S. Environmental Protection Agency ${ }^{14}$. The CCC is an estimate of the highest concentration of a material in the surface water to which an aquatic community can be exposed indefinitely without resulting in an unacceptable effect $^{14}$. Individual water samples generally displayed a wide difference in metal concentrations during the sampling events, indicating not only the temporal but the spatial variation among each sampling sites. With the exception of $\mathrm{Cr}$, contents of heavy metals and trace elements in sewage effluents seemed relatively higher than that in the Fazih and the Wu River. While the highest mean concentration of 

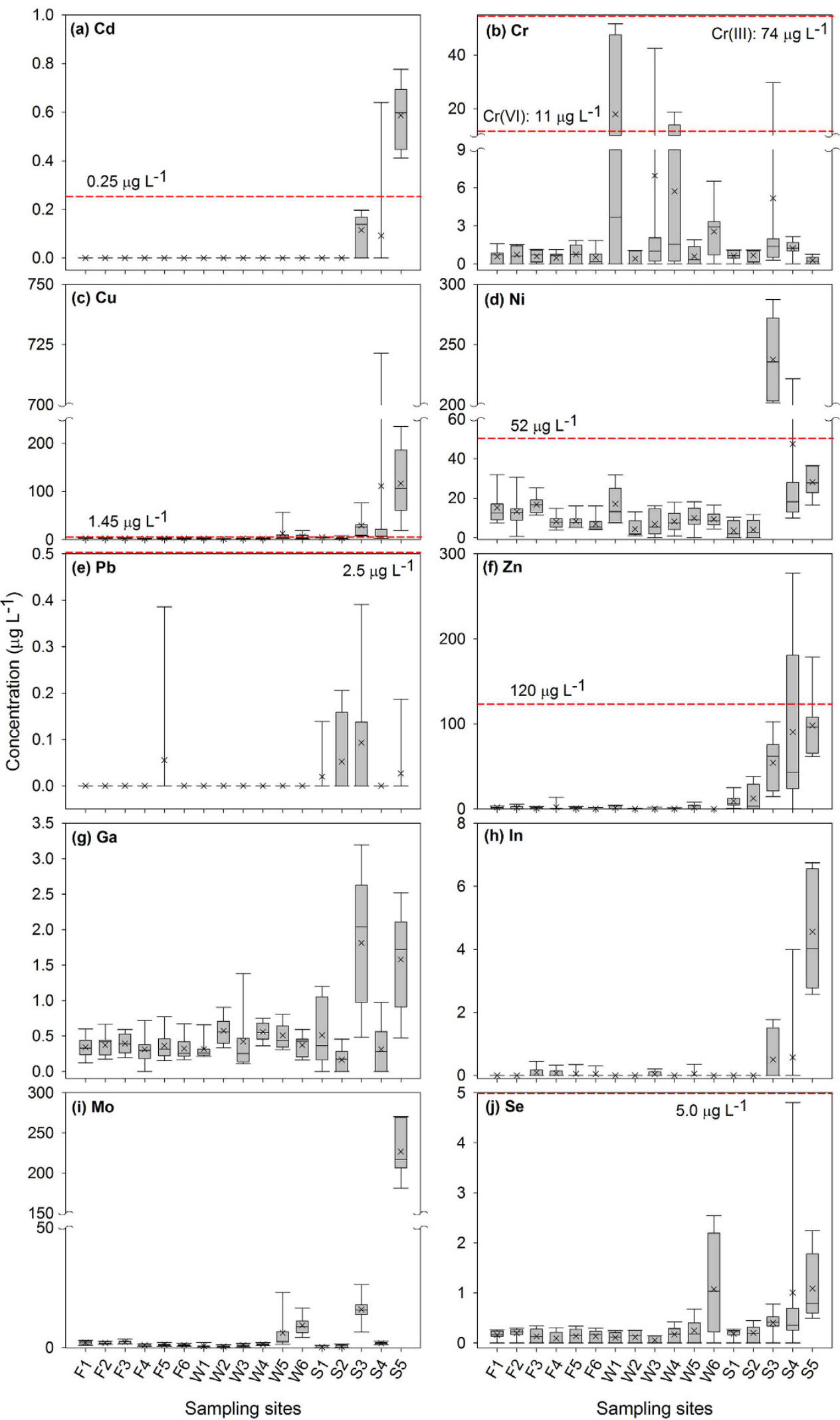

Figure 3. Metals contents for river waters sampled from the Fazih (F1 F6) and the Wu (W1 W6) River, and the sewage sampled from effluent outlets (S1-S5). Dash lines are values of the Criterion Continuous Concentration (CCC) established by the USEPA. Currently there is no CCC available for Ga, In, and Mo. 
$\mathrm{Cd}\left(0.59 \mu \mathrm{g} \mathrm{L}^{-1}\right), \mathrm{Cu}\left(116.35 \mu \mathrm{g} \mathrm{L}^{-1}\right), \mathrm{Ni}\left(237.60 \mu \mathrm{g} \mathrm{L}^{-1}\right), \mathrm{Pb}\left(0.09 \mu \mathrm{g} \mathrm{L}^{-1}\right), \mathrm{Zn}\left(98.01 \mu \mathrm{g} \mathrm{L}^{-1}\right), \mathrm{Ga}\left(1.81 \mu \mathrm{g} \mathrm{L}^{-1}\right), \mathrm{In}$ $\left(4.56 \mu \mathrm{g} \mathrm{L}^{-1}\right)$, Mo $\left(226.64 \mu \mathrm{g} \mathrm{L}^{-1}\right)$, and Se $\left(1.09 \mu \mathrm{g} \mathrm{L}^{-1}\right)$ was found in the site of S3 or S5, the highest mean amount of $\mathrm{Cr}\left(17.89 \mu \mathrm{g} \mathrm{L}^{-1}\right)$ was found in the W1 site. Given that S3 and S5 were sewage effluents discharged mainly from the traditional and semiconductor industries, it is not surprising to observe substantial amounts of heavy metals in these samples. However, the occurrence of $\mathrm{Cr}$ in the W1, which exceeded the CCC, implying a peculiar source to $\mathrm{Cr}$ discharges.

Heavy metals and trace elements in sediments. The maximum, mean, median, and minimum concentration of heavy metals $(\mathrm{Cd}, \mathrm{Cr}, \mathrm{Cu}, \mathrm{Ni}, \mathrm{Pb}, \mathrm{Zn})$ and trace elements ( $\mathrm{Ga}, \mathrm{In}, \mathrm{Mo}, \mathrm{Se})$ in sediments were summarized in Fig. 4. Metal concentrations were evaluated by the comparison with the probable effect level (PEL - dash lines in Fig. 4) established by the Canadian Council of Ministers of the Environment (CCME- ${ }^{15}$ ). Once metal concentrations exceed the PEL, adverse biological effects are expected to occur frequently. Such definition is based on the premise that the probability of toxic effects resulted from exposures to a given chemical increases with the concentration of that substance in sediments ${ }^{15,16}$.

Generally, sediments in the Fazih River seemed contain relatively higher amounts of heavy metals and trace elements than that in the Wu River. Plausible explanations include: (1) the Fazih River has contained the discharged sewage effluent from hospitals (S1 and S1) and traditional industrial activities (S3 and S4 - Fig. 1); (2) average volume rates of the water flow in the Fazih River $\left(10.58 \mathrm{~m}^{3} / \mathrm{s}\right)$ is less than that in the Wu River $\left(114.43 \mathrm{~m}^{3} / \mathrm{s}\right)$, resulting in a relatively limited mobilization of suspended particles and thereby a net deposition and accumulation of particulate metals in the Fazih River ${ }^{17}$; (3) the memory effect for metal accumulation from the previous sewage effluents discharged from the CTSP. The effluent outlet of the CTSP was relocated to the S5 site in December, 2009.

Although distribution of heavy metals and trace elements varied essentially among individual sites along the Fazih and the $\mathrm{Wu}$ River, the contamination of $\mathrm{Cr}$ and $\mathrm{Zn}$ is generally critical while compared with the PEL. For $\mathrm{Cr}$, the highest level of $357.35 \mathrm{mg} \mathrm{kg}^{-1}$ was observed at the $\mathrm{F} 6$ site with the mean of $169.03 \mathrm{mg} \mathrm{kg}^{-1}$. In addition, sampling sites wherein both mean and median concentrations of $\mathrm{Cr}$ exceeded the PEL all located in the Fazih River (F2, F3, and F6). Similar trend was found for the Zn distribution. Only F2, F3, and F6 sites were exceeded in mean and median concentrations of $\mathrm{Zn}$.

Given that the PEL for Ni, Ga, In, Mo, and Se has not been established yet ${ }^{15}$, we are not able to assess the environmental risk for such elements currently. However, among all tested trace elements, Se is particularly of interest to environmental scientists due to the narrow range between nutritionally required and toxic effect in organisms ${ }^{18}$. Literatures have strongly indicated that chronic Se toxicity could be triggered by the movement from the accumulation in the sediment into the food chain ${ }^{19}$. The threshold for biological toxic effects of Se ranged from 2 to $4 \mathrm{mg} \mathrm{kg}^{-120,21}$, wherein the classification system of ${ }^{20}$ that claimed the threshold of $2 \mathrm{mg} \mathrm{kg}^{-1}$ is more robust due to the more comprehensive computation for Se aquatic hazard assessments ${ }^{22}$. Such threshold was exceeded by the mean Se content of $2.05 \mathrm{mg} \mathrm{kg}^{-1}$ in the F3 sample.

Ecological risk indices. Given that our study basin received pollution from multiple heavy metals, we used the quantitative approach developed by Hakanson ${ }^{23}$ to evaluate the potential ecological risk of heavy metal pollutions in sediments. The potential ecological risk index $(R I)$ is defined as Equation (1).

$$
R I=\sum_{i=1}^{n}\left(T_{i} \times \frac{C_{i}}{C_{0}}\right)
$$

where $T_{\mathrm{i}}$ is the toxic-response factor for a given substance (e.g., $\left.\mathrm{Cd}=30, \mathrm{Cr}=2, \mathrm{Cu}=\mathrm{Ni}=\mathrm{Pb}=5, \mathrm{Zn}=1\right)^{23,24}$; $C_{\mathrm{i}}$ is the metal concentration in sediments; $C_{0}$ is the regional background concentration of heavy metals, wherein we used the metal concentration obtained from the W2 site as the background because W2 received relatively less industrial and domestic sewage.

The $R I$ of heavy metals in sediment samples were categorized into three zones as shown in Fig. 5. The following terminology was used to access the potential ecological risk for the basin indicated by the $R I$ value $^{23}$ :

$$
\begin{aligned}
& R I<150 \rightarrow \text { low ecological risk } \\
150 \leq & R I<300 \rightarrow \text { moderate ecological risk } \\
300 \leq & R I<600 \rightarrow \text { considerable ecological risk } \\
& R I \geq 600 \rightarrow \text { very high ecological risk }
\end{aligned}
$$

In our studied basin, the $R I$ values for the Wu River sediments were generally lower than 300 . However, four out of six sediment samples in the Fazih River showed the RI values ranging from 300 to 600, suggesting a considerable ecological risk in this basin. Given that the toxic response factor for trace elements such as Ga, In, Mo, and Se have not been developed well yet, the potential ecological risk of such trace elements were excluded here.

Principal component analysis. The PCA has been applied to determine the correlation between the partition of discharged metals and environmental factors such as $\mathrm{pH}, \mathrm{EC}, \mathrm{ORP}, \mathrm{TOC}$, and amorphous $\mathrm{Fe}$ and $\mathrm{Al}^{7,8,25-27}$. Results of PCA for metal contents in water samples and fluvial environmental factors of $\mathrm{pH}, \mathrm{EC}$, and ORP were showed in Fig. 6a. The PCA results suggested that heavy metals, trace elements, and environmental factors could be grouped into a four-component model, which accounted for $71.0 \%$ of the total variance (Tables S1 and S2 in Supplementary Materials). The first principal component that showed a contribution rate of $35.3 \%$ correlated with $\mathrm{Cd}, \mathrm{In}, \mathrm{Mo}, \mathrm{Cu}, \mathrm{Se}$, and $\mathrm{Zn}$. For the $2^{\text {nd }}$ component that accounted for $15.4 \%$ of variance, metals of $\mathrm{Pb}, \mathrm{Ni}$, and $\mathrm{Ga}$ were grouped into the environmental factor of EC. However, the other environmental factors of $\mathrm{pH}$ and 

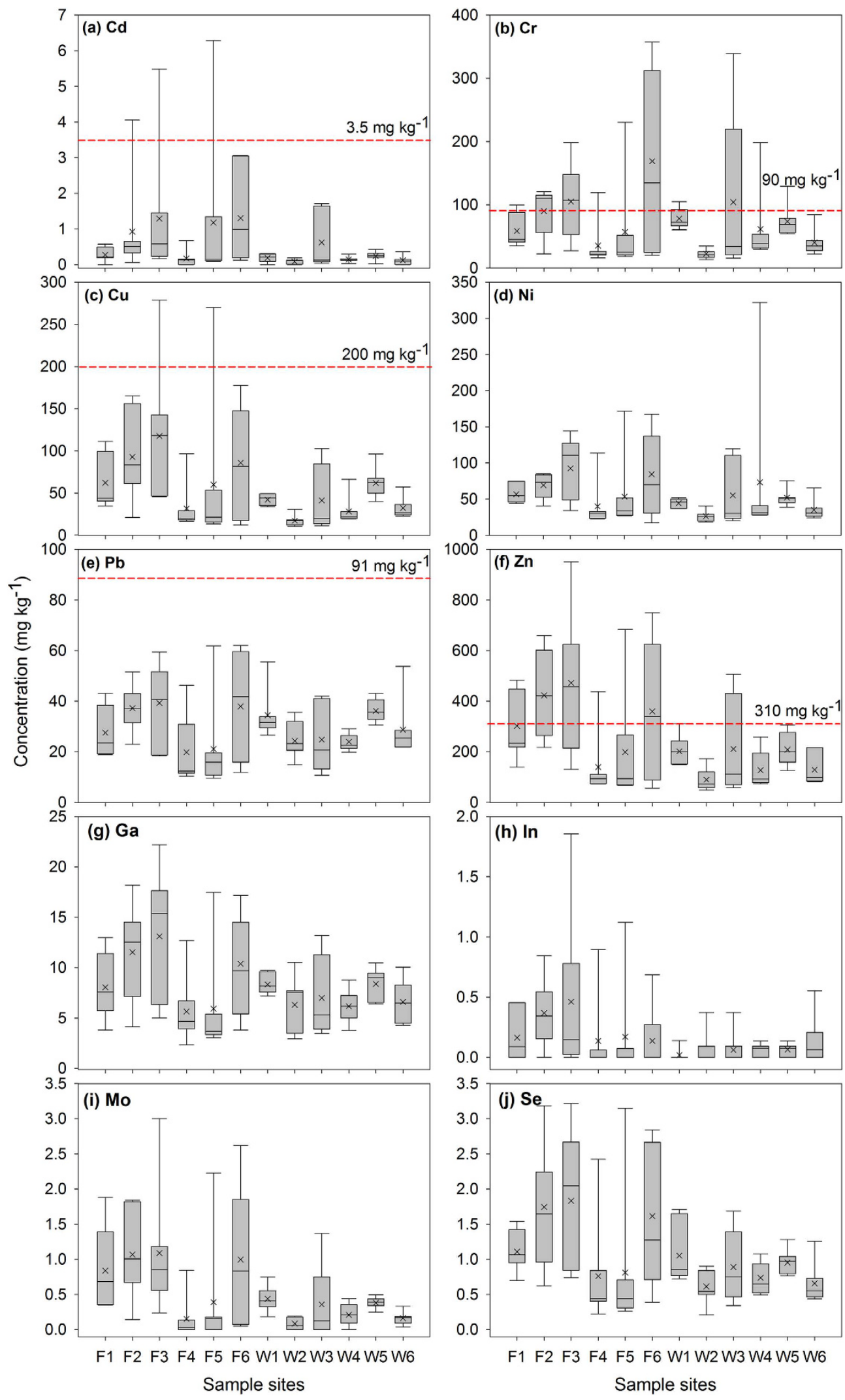

Figure 4. Metals contents of sediments sampled from the Fazih (F1 F6) and the Wu (W1 W6) River. Dash lines are values of the probable effect level (PEL) established by the Canadian Council of Ministers of Environment (CCME). Currently there is no PEL available for Ni, Ga, In, Mo, and Se. 


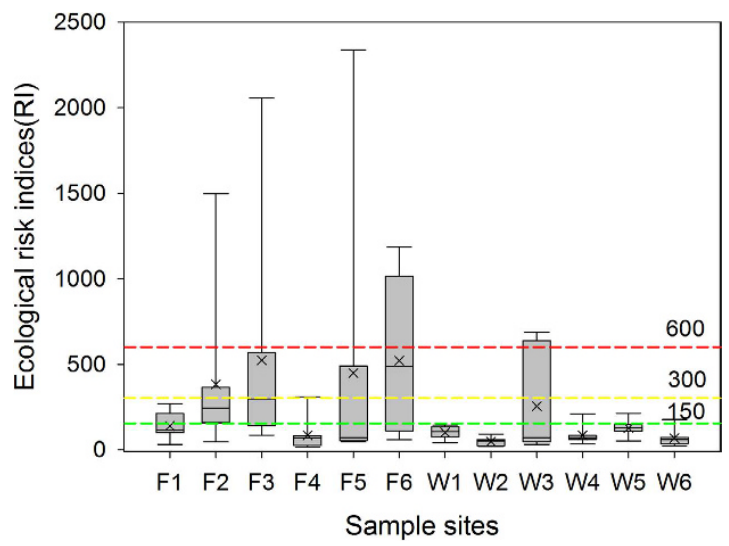

Figure 5. Ecological risk indices (RI) for sediments sampled from the Fazih (F1 F6) and the Wu (W1 W6) River. The $R I$ values of 150,300 , and 600 are the boundaries to determine the potential ecological risk.
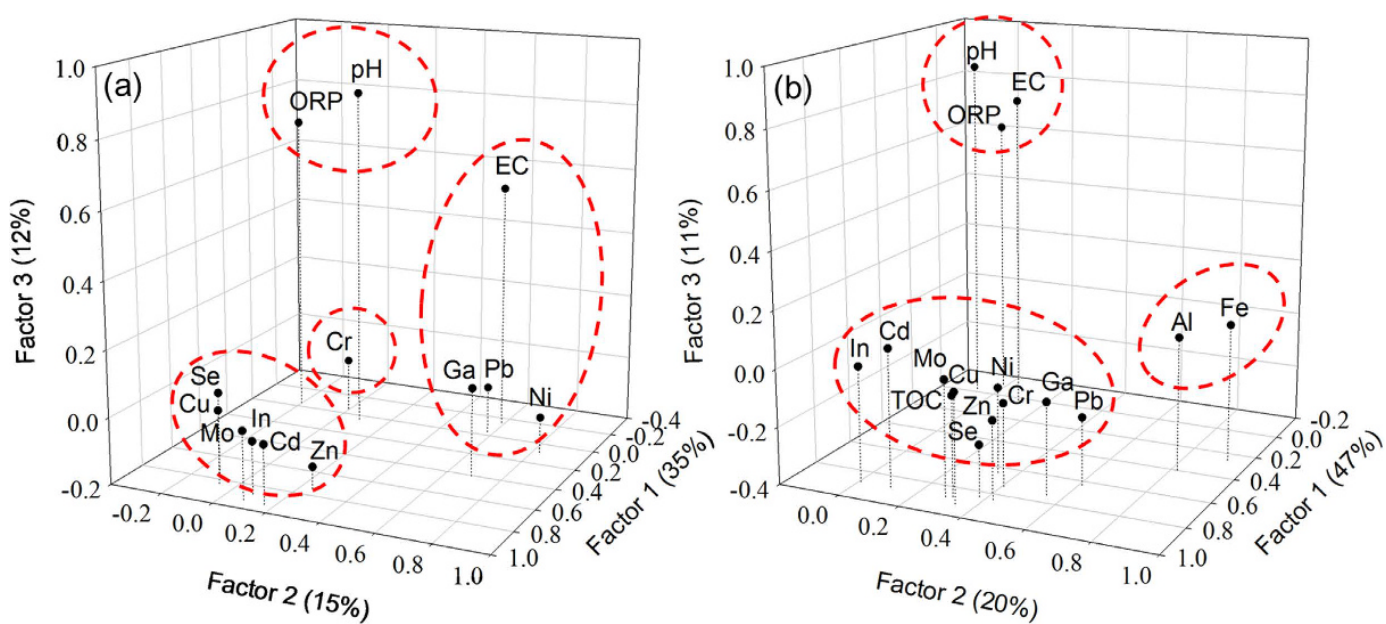

Figure 6. Plots of the PCA based on metal concentrations and environmental factors in (a) water and (b) sediment samples.

ORP did not correlate with any metals (the $3^{\text {rd }}$ component with $12.0 \%$ of variance). Most noteworthily, Cr was isolated from all other metals and environmental factors (the $4^{\text {th }}$ component with $8.2 \%$ of variance). Such results implied that discharged heavy metals and trace elements could be categorized into three groups: (1) Cd, In, Mo, $\mathrm{Cu}$, Se, $\mathrm{Zn}$; (2) Pb, Ni, Ga; (3) Cr. In addition, the environmental factors of $\mathrm{pH}$ and ORP showed no correlation with the metal effluent. Only $\mathrm{EC}$ might influence the distribution of $\mathrm{Pb}, \mathrm{Ni}$, and $\mathrm{Ga}$ in river water.

For sediment samples, we added the contents of three more environmental factors including TOC, oxalate-extractable Fe and Al of individual sediment samples to process the PCA. According to Table S3 and S4 in Supplementary Materials, the matrix of 16 features (10 metals and 6 environmental factors) was grouped into a three-component model, describing approximately $77.7 \%$ of the total variance (Fig. $6 \mathrm{~b}$ ). The first component that described $46.9 \%$ of the total variance was highly loaded by all heavy metals, trace elements, and TOC. The amorphous $\mathrm{Fe}$ and $\mathrm{Al}$ were grouped together and represented as the second component with $19.6 \%$ of the total variance. For other environmental factors of $\mathrm{pH}$ ORP, and EC, they were classified as the third component, describing $11.2 \%$ of the total variance. In contrast to water samples, it is not able to classify metals in sediment samples into groups. All heavy metals and trace elements were correlated to TOC contents in sediments, implying OM mainly controlled the retention and further the distribution of metals in sediments. Neither solid-phase-related factors of amorphous $\mathrm{Fe}$ and $\mathrm{Al}$ nor solution-related factors of $\mathrm{pH}$ ORP, and EC showed the essential relationship for the metal retention in sediments.

Retention of heavy metals and trace elements in sediments. By coupling the PCA results of water and sediment samples, the noteworthy finding for the metal distribution in our study river basin was that the correlation between discharged metals suggested by the PCA of water samples vanished in sediment samples. The disagreement in metal correlation between water and sediment samples is of interest to us in terms of (1) the rationale to use the metal contents in sediments for the identification of pollution sources ${ }^{6,7,25}$, (2) why the metal retention in sediments is highly correlated to TOC contents rather than other environmental factors, and (3) whether the metal species changes during the partition between solution-solid interfaces. 


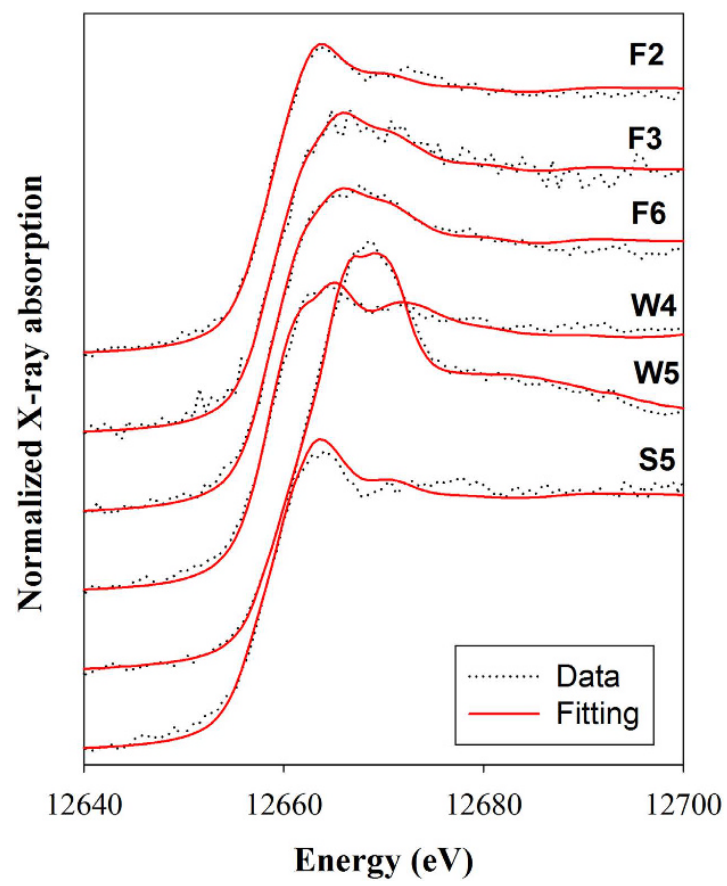

Figure 7. Selenium K-edge XANES spectra (dashed lines) and results of linear combination fitting (solid lines) for sediments collected in the Fazih (F2, F3, and F6) and the Wu (W4 and W5) River as well as suspension solids collected from the effluent outlet of $\mathrm{S5}$.

Widespread evidences have existed for the incorporation and retention of metals into OM and Fe-(hydr) oxides in soils and bed sediments ${ }^{5,25,28-31}$. In our study, however, the metal distribution in sediments only significantly correlated to the OM (TOC) contents. The OM has been widely recognized as a variable-charged material that consists of various functional groups such as carboxyl (R-COOH), phenolic OH (aromatic-OH), alcoholic $\mathrm{OH}\left(\mathrm{R}-\mathrm{CH}_{2}-\mathrm{OH}\right)$, and carbonyl $(\mathrm{R}-\mathrm{C}=\mathrm{O}-\mathrm{R}-\mathrm{R} / \mathrm{H} / \mathrm{OR})^{32}$. Moreover, the $\mathrm{OM}$ also contains amine and amide groups as basic functional groups. Given that the dissociation constant $\left(\mathrm{pK}_{\mathrm{a}}\right)$ for carboxyl and phenolic groups ranges from 3-5 and 5-7, surfaces of natural OM are generally covered with negative charges while $\mathrm{pH}>3^{33}$. In the contrary, surfaces of Fe-(hydr)oxides are often positively charged at neutral $\mathrm{pH}$ as their point of zero charge is generally $>\mathrm{pH} 8^{34-36}$. The species of metals would vary depending on the coupling of $\mathrm{pH}$ and redox potential in environments. With the exception of $\mathrm{Se}$ and Mo that occurred mainly as elemental species $\left(\mathrm{Se}_{(\mathrm{s})}\right)$ or oxyanions $\left(\mathrm{HSeO}_{3}{ }^{-}\right.$and $\mathrm{MnO}_{4}{ }^{2-}$ ) under the environmental conditions of our study sites (Fig. 2), other metals generally presented as cations $\left(\mathrm{Cu}^{+} / \mathrm{Cu}^{2+}, \mathrm{Ni}^{2+}, \mathrm{Zn}^{2+}\right.$, etc. $)$ or hydrolyzed species $\left(\mathrm{Cr}(\mathrm{OH})^{2+}, \mathrm{Pb}(\mathrm{OH})^{+} \text {, etc. }\right)^{37}$. Compared with Fe-(hydr)oxdies, thereby, most of metals might prefer to be retained by OM through the electrostatic attraction under circumambient environments. Similar trends in soils and sediments were reported by several scientists. Although Fe can stabilize metals by adsorption or coprecipitation with $\mathrm{Fe}$-(hydr)oxides ${ }^{29-31}$, OM could act as a major sink for metals due to its strong complexing capacity ${ }^{38-40}$. For example, Grybos et al..$^{28}$ evidenced that soil $\mathrm{OM}$ could be a more important sink for trace metals such as rare earth elements, $\mathrm{Pb}$, and $\mathrm{Ni}$ than $\mathrm{Fe}$-(hydr)oxides. The partition of $\mathrm{Ni}$ onto $\mathrm{OM}$ would increase with increasing $\mathrm{pH}^{41}$. For $\mathrm{Cr}$ and $\mathrm{Cu}, \mathrm{OM}$ is also an important source although which cannot be quantified precisely due to the precipitation or re-adsorption ${ }^{28}$. In addition, Pan et al. ${ }^{42}$ also indicated that $\mathrm{OM}$ is the most important adsorption surface for the $\mathrm{Cu}, \mathrm{Cd}, \mathrm{Pb}$, and $\mathrm{Ni}$ in paddy soils ${ }^{42}$.

Prior to the retention onto sediments, metals discharged from sewage effluents might transport in the form of soluble species in solutions and/or insoluble species in suspended solids. Taken into account that the metal concentrations in suspended particles were generally higher than that in bed sediments and/or even exceeded the PEL guidelines for the protection of aquatic life ${ }^{43}$, we were wondering whether any species transformations of metals in suspended solids occurred as the consequence of retention onto sediments. Here, Se speciation in suspended solids and sediments was performed as an example to examine the species transformation in relation to changes in environmental conditions.

Selenium speciation. Selenium speciation in selected suspended solids and sediments was performed using XANES analysis. Tested suspended solids and sediments were collected in January, 2015. Selenium concentrations for the Fazih River sediments (F2, F3, and F6) ranged from 2.17 to $3.18 \mathrm{mg} \mathrm{kg}^{-1}$, and that for the Wu River sediments (W4 and W5) were lower than $1 \mathrm{mg} \mathrm{kg}^{-1}$. However, in suspended solids (S5), the Se content was up to $65.2 \mathrm{mg} \mathrm{kg}^{-1}$, which was 20 to 60 times higher than that of sediments in the river basin. XANES data in Fig. 7 showed an essential spectral variation across all samples. According to the spectral features, the samples could be classified into three groups. The first one is the F2, W4, and S5, whose position of the white line peak located around 12663.5-12664.5eV. The second group consists of F3 and F6 samples as they showed a similar white line 


\begin{tabular}{|c|c|c|c|c|c|c|c|}
\hline Sample name & $\operatorname{Se}\left(\mathbf{m g ~ K g} \mathbf{g}^{-1}\right)$ & $\begin{array}{c}\text { FeSe } \\
(\mathrm{mol} \%)^{b}\end{array}$ & $\begin{array}{c}\text { Elemental } \\
\mathrm{Se}^{0}(\mathrm{~mol} \%)^{\mathrm{b}}\end{array}$ & $\begin{array}{c}\text { Trimethyl- selenonium } \\
(\mathrm{mol} \%)^{\mathbf{b}}\end{array}$ & $\begin{array}{l}\text { Selenite } \\
(\mathrm{mol} \%)^{\mathrm{b}}\end{array}$ & $\begin{array}{l}\text { Selenate } \\
(\mathrm{mol} \%)^{\mathrm{b}}\end{array}$ & $\begin{array}{c}\text { R-factor } \\
\left(\times 10^{3}\right)\end{array}$ \\
\hline $\mathrm{F} 2$ & $3.18 \pm 0.12$ & $60.7 \pm 2.3$ & $39.3 \pm 2.3$ & & & & 1.64 \\
\hline F3 & $2.17 \pm 1.64$ & $76.8 \pm 3.3$ & & $23.2 \pm 3.3$ & & & 4.78 \\
\hline F6 & $2.84 \pm 0.38$ & $79.8 \pm 1.9$ & & $20.2 \pm 1.9$ & & & 1.40 \\
\hline W4 & $0.94 \pm 0.08$ & $57.3 \pm 1.8$ & & $42.7 \pm 1.7$ & & & 2.44 \\
\hline W5 & $0.97 \pm 0.06$ & $58.2 \pm 1.3$ & & & $27 \pm 0.9$ & $14.8 \pm 0.7$ & 1.37 \\
\hline S5 & $65.2 \pm 4.11$ & $61.8 \pm 3.3$ & $38.2 \pm 3.3$ & & & & 2.96 \\
\hline
\end{tabular}

Table 1. Linear combination fitting results for Se K-edge XANES spectra of sediments collected in the Fazih (F2, F3, and F6) and the Wu (W4 and W5) River as well as suspension solids collected from the effluent outlet of S5. The data show the proportion (in units of mol\% ) of the reference spectra that resulted

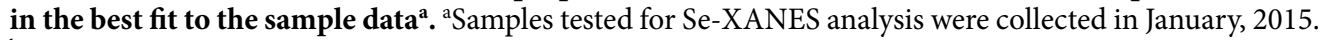
${ }^{\mathrm{b}}$ Mean \pm standard deviation. The weighting factors on each fit were summed to $100 \pm 1 \%$ and were normalized to $100 \%$. ${ }^{c}$ Normalized sum of the squared residuals of the fit $\left(R-\right.$ factor $\left.=\sum(\text { data }- \text { fit })^{2} / \sum \mathrm{data}^{2}\right)$.

peak at approximate $12666.7 \mathrm{eV}$. For the W5 samples, its spectral features significantly differed from other samples, wherein the position of the white line peak shifted to relatively higher energy at $12668.7 \mathrm{eV}$.

The presence and proportion of Se species in suspended solids and sediments were determined using LCF with spectra obtained from reference materials including iron selenide, elemental $\mathrm{Se}^{0}$, selenomethionine, selenocystine, trimethylselenonium, selenite, and selenate. Results of LCF shown as solid lines in Fig. 7 and Table 1 indicated that the Se inventory in all samples was dominated mainly by FeSe $(>57 \%)$. Such selenide could be originated from materials like CdSe and ZnSeused in semiconductor industries ${ }^{44}$. For the F2 and S5 samples, the elementary $\mathrm{Se}^{0}$ contributed about $38 \%$ of the total Se besides the FeSe. However, in the samples of F3, F6, and W4, not only inorganic FeSe but organic Se of trimethylselenonium was found. The most concerned point is that Se oxyanions (selenite and selenate) was observed at the W5 site, wherein the sediment received a massive amount of Se from the suspended solids of S5. Selenite and selenate are highly soluble, hence more mobile than the less soluble forms such as selenide and elemental $\mathrm{Se}^{045}$. In addition, selenite poses an approximately 10 -fold higher bioaccumulation factor than selenate for the phytoplankton Se uptake ${ }^{46}$. In term of toxicity, the relative sequence for individual Se species is: selenite $>$ selenate $>$ selenide $>$ elemental $\mathrm{Se}^{047}$. Although organo-Se are less soluble, they are relatively readily absorbed by organisms ${ }^{48}$. To sum up, the apparent discrepancy in Se species over the course of transportation processes may be caused by the various environmental conditions between waters and sediments. Hence, a further study to determine the transformation of metal species in relation to various environmental conditions is merited for undertaking environmental risk assessments and understanding metal distribution and transfer into the food chain in ecosystems.

\section{Discussion}

One of the major environmental impacts for the metal accumulation in sediments was the metal uptake by primary producers and the subsequent access into the food webs of aquatic ecosystems. In this study, the distribution and accumulation of heavy metals and trace elements in relational to environmental factors in the basin of the Fazih and the $\mathrm{Wu}$ River that received sewage effluents from traditional and semiconductor industrial activities was determined by PCA. The PCA results pointed out the discrepancy in metal distributions between water and sediment samples. Although PCA for water samples proposed three potential origins of contamination for heavy metals and trace elements, such metal distribution was not observed while metals accumulated in sediments. Among all tested environmental factors, the metal distribution in sediments only correlated to OM contents. In spite of other environmental factors such as $\mathrm{pH}$ and ORP did not directly influenced the metal distribution in sediments, such physical-chemical properties in environments may control the species transformation for metals and further change their mobility, bioavailability, and toxicity. Our XANES results indicated that Se inventory mainly comprised selenide and elemental $\mathrm{Se}^{0}$ in suspended solids collected from sewage effluents. However, selenite and selenate was found in the sediment received a massive amount of Se from suspended solids. This is of environmental concern as selenite and selenate could bioaccumulate in organisms and thus incorporate into food webs more readily than selenide and elemental $\mathrm{Se}^{0}$.

Collectively, our results clearly suggest that $\mathrm{OM}$ must be taken into account to assess the metal behavior in sediments. Recognition of the roles of environmental factors in metal distribution could lead to a better quantification in dynamics and mass balances for metals in contaminated ecosystems. Given that bed sediments serve both as a sink and source of metals, the prediction of relative abundance of metals in sediments could improve strategies for the management and remediation of metal contamination. Conclusively, the consideration of environmental factors, especially OM, is required while monitoring metal accumulation in sediments. Such comprehensive information can help to develop an adequate protection and restoration plan.

\section{Methods}

Study areas and sample collection. The water and sediment samples were collected from 12 sampling sites scattered in the Fazih (F1-F6) and the Wu (W1-W6) River (Fig. 1). Sewage effluents discharged from hospitals (S1 and S2), the Taichung Industrial Park (S3), the Taichung Precision Machinery Innovation Technology Park (S4), and the Central Taiwan Science Park (CTSP, S5) were also collected. There were seven sampling events during June, 2014 to August, 2015. 
Water samples were collected at river surfaces or from sewage effluents. The $\mathrm{pH}, \mathrm{EC}$, and ORP data of water samples were determined using a multi-parameter water quality checker (Horiba U-50) immediately after the collection. Once in the laboratory, the other portion of water samples was filtered through a $0.2 \mu \mathrm{m}$ membrane, acidified to a $2 \% \mathrm{HNO}_{3}$ background, and preserved in acid-washed polyethylene bottles at $4{ }^{\circ} \mathrm{C}$. For sediments, approximately $100 \mathrm{~g}$ of solids were collected using a plastic scoop from the top $2 \mathrm{~cm}$ of bottom sediments and preserved in acid-washed polyethylene containers at $4^{\circ} \mathrm{C}$. Sediment samples were air-dried inside a laminar flow chamber, passed through a $2-\mathrm{mm}$ nylon sieve, and ground in an agate mortar. For elemental analysis, $1 \mathrm{~g}$ of pretreated sediment was acid digested using $10 \mathrm{~mL}$ of aqua regia at $180^{\circ} \mathrm{C}$ for $4 \mathrm{~h}$. Metal concentrations in acid digestates were determined by inductively coupled plasma mass spectrometry (ICP-MS, Elan DRC II, PerkinElmer) with methane as reaction gas to reduce interatomic interferences. A soil standard reference material (SRM, CRM029 from Sigma-Aldrich) was also digested to check the analysis recovery. Three replicates were performed in acid digestion for each sample including blank and SRM for quality control. The recoveries of the SRM ranged from 80 to $120 \%$ in all metals. Contents of OM in sediments were determined by amounts total organic carbon (TOC), which was determined using the TOC analyzer (Multi N/C 2100, Analytik Jena). Sediment samples for TOC analysis were pretreated using $10 \%$ phosphoric acid overnight to reduce the interference from inorganic carbon $^{49,50}$. The amorphous $\mathrm{Fe}$ and $\mathrm{Al}$ contents in sediments were determined using acid ammonium oxalate extraction method ${ }^{51}$. Briefly, $20 \mathrm{~mL}$ of $0.2 \mathrm{M}$ acidified ammonium oxalate was added to $0.5 \mathrm{~g}$ of pretreated sediments. Suspensions were shaken horizontally in darkness for $2 \mathrm{~h}$ and then centrifuged. The $\mathrm{Fe}$ and $\mathrm{Al}$ amounts in supernatant were determined using the ICP-MS.

Principal component analysis. Principal component analysis (PCA) has been often used to interpret the multivariate, complex, redundant, and not direct data ${ }^{52-54}$. Here, we used PCA to determine the correlation of metal discharges and to understand the role of environmental factors that affect the metal retention in sediments. The PCA reduces variables into a set of principal components and gives a new multidimensional system. The PCA and correlation analysis were performed using the SPSS 19.0 software $\left(\right.$ IBM $\left.^{\circledR}\right)$ for the Windows. To interpret the results more precisely, the rotation method - Varimax with Kaiser Normalization - was applied to maximize variances of the squared normalized factor loadings across variables for each factor. All principal factors extracted from variables were those whose eigenvalues is higher than $1^{55}$.

Data collection and analysis for Se K-edge XANES spectroscopy. Selenium speciation in selected sediments and suspended solids was determined using Se K-edge XANES analysis. Suspended solids were collected by filtering the sewage effluent at the $\mathrm{S} 5$ site thought a mixed cellulose esters membrane with a calibrated porosity of $0.2 \mu \mathrm{m}$ (Millipore). The filter membrane was placed on a standing stainless steel filter holder ( $90 \mathrm{~mm}$, Millipore) and the filtration was operated under an air pressure of 65 psi. All samples for Se-XANES analysis were prepared by mounting approximately $0.2 \mathrm{~g}$ solids in acrylic sample holders, sealing with Kapton tape to avoid desiccation. Spectra were acquired at the Beamline BL17C1 at the National Synchrotron Radiation Research Center (NSRRC), Hsinchu, Taiwan. The linear combination fitting (LCF) of Se-XANES data across from $30 \mathrm{eV}$ below to $40 \mathrm{eV}$ above the Se absorption edge was used to determine the Se species. Reference materials used in LCF included iron selenide (FeSe), elemental (gray) $\mathrm{Se}^{0}$, selenomethionine, selenocystine, trimethylselenonium, selenite $\left(\mathrm{H}_{2} \mathrm{SeO}_{3}\right)$, and selenate $\left(\mathrm{H}_{2} \mathrm{SeO}_{4}\right)$. See Liu, et al. ${ }^{45}$ for additional details in data collection and processing.

\section{References}

1. National Research Council. Contaminated Marine Sediments: Assessment and Remediation. (National Academies Press, 1989).

2. Harbison, P. Mangrove muds - A sink and a source for trace metals. Mar. Pollut. Bull. 17, 246-250, doi: 10.1016/0025-326X(86)90057-3 (1986).

3. Chen, W., Tan, S. K. \& Tay, J. H. Distribution, fractional composition and release of sediment-bound heavy metals in tropical reservoirs. Water, Air, Soil Pollut. 92, 273-287, doi: 10.1007/BF00283563 (1996).

4. Salomons, W. \& Stigliani, W. Biogeodynamics of pollutants in soils and sediments. (Springer-Verlag, 1995).

5. Yu, K.-C., Tsai, L.-J., Chen, S.-H. \& Ho, S.-T. Correlation analyses on binding behavior of heavy metals with sediment matrices. Water Res. 35, 2417-2428, doi: 10.1016/S0043-1354(00)00518-2 (2001).

6. Singh, K., Malik, A., Sinha, S., Singh, V. \& Murthy, R. Estimation of Source of Heavy Metal Contamination in Sediments of Gomti River (India) using Principal Component Analysis. Water, Air, Soil Pollut. 166, 321-341, doi: 10.1007/s11270-005-5268-5 (2005).

7. Yi, Y., Yang, Z. \& Zhang, S. Ecological risk assessment of heavy metals in sediment and human health risk assessment of heavy metals in fishes in the middle and lower reaches of the Yangtze River basin. Environ. Pollut. 159, 2575-2585, doi: 10.1016/j. envpol.2011.06.011 (2011).

8. Tam, N. F. Y. \& Wong, Y. S. Spatial variation of heavy metals in surface sediments of Hong Kong mangrove swamps. Environ. Pollut. 110, 195-205, doi: 10.1016/S0269-7491(99)00310-3 (2000).

9. Wuana, R. A. \& Okieimen, F. E. Heavy metals in contaminated soils: a review of sources, chemistry, risks and best available strategies for remediation. ISRN Ecol. 2011, 20, doi: 10.5402/2011/402647 (2011).

10. Abdel-Shafy, H. I., Hegemann, W. \& Genschow, E. Fate of heavy metals in the leather tanning industrial wastewater using an anaerobic process. Environ. Manage. Health 6, 28-33, doi: 10.1108/09566169510085135 (1995).

11. Bizzo, W., Figueiredo, R. \& de Andrade, V. Characterization of printed circuit boards for metal and energy recovery after milling and mechanical separation. Materials 7, 4555 (2014).

12. Barakat, M. A. New trends in removing heavy metals from industrial wastewater. Arabian Journal of Chemistry 4, 361-377, doi: 10.1016/j.arabjc.2010.07.019(2011).

13. Becking, L. G. M. B., Kaplan, I. R. \& Moore, D. Limits of the natural environment in terms of pH and oxidation-reduction potentials. J. Geol. 68, 243-284 (1960).

14. U.S. EPA. National Recommended Water Quality Criteria. (U.S. Environmental Protection Agency, Washington,DC, USA, 2009).

15. MDEPQ, E. Criteria for the assessment of sediment quality in Quebec and application frameworks: prevention, dredging and remediation. (Quebec, Canada, 2007).

16. Macdonald, D., Carr, R. S., Calder, F., Long, E. \& Ingersoll, C. Development and evaluation of sediment quality guidelines for Florida coastal waters. Ecotoxicology 5, 253-278, doi: 10.1007/BF00118995 (1996).

17. Trimble, S. W. In Sediment Cascades: An Integrated Approach (eds T. Burt \& R. Allison) (John Wiley \& Sons, 2010). 
18. Ralston, N. V. C., Unrine, J. \& Wallschläger, D. Biogeochemistry and Analysis of Selenium and its Species. (North American Metals Council, Washington D.C., 2008).

19. Canton, S. P. \& Van Derveer, W. D. Selenium toxicity to aquatic life: An argument for sediment-based water quality criteria. Environ. Toxicol. Chem. 16, 1255-1259, doi: 10.1002/etc.5620160622 (1997).

20. Lemly, A. D. In Selenium assessment in aquatic ecosystems: A guide for hazard evaluation and water quality criteria (ed D. E. Alexander) 18-38 (Springer, 2002).

21. Van Derveer, W. D. \& Canton, S. P. Selenium sediment toxicity thresholds and derivation of water quality criteria for freshwater biota of western streams. Environ. Toxicol. Chem. 16, 1260-1268, doi: 10.1002/etc.5620160623 (1997).

22. May, T. et al. An evaluation of selenium concentrations in water, sediment, invertebrates, and fish from the Solomon River Basin. Environ. Monit. Assess. 137, 213-232, doi: 10.1007/s10661-007-9742-y (2008).

23. Hakanson, L. An ecological risk index for aquatic pollution control - A sedimentological approach. Water Res. 14, 975-1001, doi: 10.1016/0043-1354(80)90143-8 (1980).

24. Yang, Z., Wang, Y., Shen, Z., Niu, J. \& Tang, Z. Distribution and speciation of heavy metals in sediments from the mainstream, tributaries, and lakes of the Yangtze River catchment of Wuhan, China. J. Hazard. Mater. 166, 1186-1194, doi: 10.1016/j. jhazmat.2008.12.034 (2009).

25. Filgueiras, A. V., Lavilla, I. \& Bendicho, C. Evaluation of distribution, mobility and binding behaviour of heavy metals in surficial sediments of Louro River (Galicia, Spain) using chemometric analysis: a case study. Sci. Total Environ. 330, 115-129, doi: 10.1016/j. scitotenv.2004.03.038 (2004).

26. Facchinelli, A., Sacchi, E. \& Mallen, L. Multivariate statistical and GIS-based approach to identify heavy metal sources in soils. Environ. Pollut. 114, 313-324, doi: 10.1016/S0269-7491(00)00243-8 (2001).

27. Sun, Y., Zhou, Q., Xie, X. \& Liu, R. Spatial, sources and risk assessment of heavy metal contamination of urban soils in typical regions of Shenyang, China. J. Hazard. Mater. 174, 455-462, doi: 10.1016/j.jhazmat.2009.09.074 (2010).

28. Grybos, M., Davranche, M., Gruau, G. \& Petitjean, P. Is trace metal release in wetland soils controlled by organic matter mobility or Fe-oxyhydroxides reduction? J. Colloid Interface Sci. 314, 490-501, doi: 10.1016/j.jcis.2007.04.062 (2007).

29. Mustafa, G., Singh, B. \& Kookana, R. S. Cadmium adsorption and desorption behaviour on goethite at low equilibrium concentrations: effects of pH and index cations. Chemosphere 57, 1325-1333, doi: 10.1016/j.chemosphere.2004.08.087 (2004).

30. Trivedi, P. \& Axe, L. Ni and Zn sorption to amorphous versus crystalline iron oxides: Macroscopic studies. J. Colloid Interface Sci. 244, 221-229, doi: 10.1006/jcis.2001.7970 (2001).

31. Venkataramani, B., Venkateswarlu, K. S. \& Shankar, J. Sorption properties of oxides: III. Iron oxides. J. Colloid Interface Sci. 67, 187-194, doi: 10.1016/0021-9797(78)90001-2 (1978).

32. Sparks, D. L. Environmental Soil Chemistry. 2nd edn, (Academic Press, 2003).

33. Sparks, D. L. Soil Physical Chemistry. 2nd edn, (CRC Press, 1999).

34. Violante, A. \& Pigna, M. Competitive sorption of arsenate and phosphate on different clay minerals and soils. Soil Sci. Soc. Am. J. 66, 1788-1796, doi: 10.2136/sssaj2002.1788 (2002).

35. Arai, Y. \& Sparks, D. L. ATR-FTIR spectroscopic investigation on phosphate adsorption mechanisms at the ferrihydrite-water interface. J. Colloid Interface Sci. 241, 317-326, doi: 10.1006/jcis.2001.7773 (2001).

36. Dimirkou, A., Ioannou, A. \& Doula, M. Preparation, characterization and sorption properties for phosphates of hematite, bentonite and bentonite-hematite systems. Adv. Colloid Interface Sci. 97, 37-61, doi: 10.1016/S0001-8686(01)00046-X (2002).

37. Takeno, N. Atlas of Eh-pH diagrams. 102 (National Institute of Advanced Industrial Science and TechnologyResearch Center for Deep Geological Environments, Tokyo, Japan, 2005).

38. Cabaniss, S. E. \& Shuman, M. S. Copper binding by dissolved organic matter: I. Suwannee River fulvic acid equilibria. Geochim. Cosmochim. Acta 52, 185-193, doi: 10.1016/0016-7037(88)90066-X (1988).

39. Frimmel, F. H. \& Huber, L. Influence of humic substances on the aquatic adsorption of heavy metals on defined mineral phases. Environ. Int. 22, 507-517, doi: 10.1016/0160-4120(96)00040-2 (1996).

40. Kalbitz, K. \& Wennrich, R. Mobilization of heavy metals and arsenic in polluted wetland soils and its dependence on dissolved organic matter. Sci. Total Environ. 209, 27-39, doi: 10.1016/S0048-9697(97)00302-1 (1998).

41. Christensen, J. B. \& Christensen, T. H. The effect of $\mathrm{pH}$ on the complexation of $\mathrm{Cd}, \mathrm{Ni}$ and $\mathrm{Zn}$ by dissolved organic carbon from leachate-polluted groundwater. Water Res. 34, 3743-3754, doi: 10.1016/S0043-1354(00)00127-5 (2000).

42. Pan, Y. et al. Solubility of trace metals in two contaminated paddy soils exposed to alternating flooding and drainage. Geoderma 261, 59-69, doi: 10.1016/j.geoderma.2015.07.011 (2016).

43. Apodaca, L. E., Driver, N. E. \& Bails, J. B. Occurrence, transport, and fate of trace elements, Blue River Basin, Summit County, Colorado: an integrated approach. Environ. Geol. 39, 901-913 (2000).

44. Gerion, D. et al. Synthesis and properties of biocompatible water-soluble silica-coated CdSe/ZnS semiconductor quantum dots. J. Phys. Chem. B 105, 8861-8871, doi: 10.1021/jp0105488 (2001).

45. Liu, Y.-T. et al. Selenium speciation in coal ash spilled at the Tennessee Valley Authority Kingston site. Environ. Sci. Technol. 47, 14001-14009, doi: 10.1021/es4041557 (2013).

46. Besser, J. M., Canfield, T. J. \& Lapoint, T. W. Bioaccumulation of organic and inorganic selenium in a laboratory food-chain. Environ. Toxicol. Chem. 12, 57-72, doi: 10.1897/1552-8618(1993)12[57:booais]2.0.co;2 (1993).

47. Daniels, L. A. Selenium metabolism and bioavailability. Biol. Trace Elem. Res. 54, 185-199 (1996).

48. Stolz, J. E., Basu, P., Santini, J. M. \& Oremland, R. S. Arsenic and selenium in microbial metabolism. Annu. Rev. Microbiol. 60, 107-130, doi: 10.1146/annurev.micro.60.080805.142053 (2006).

49. Pansu, M. \& Gautheyrou, J. Handbook of soil analysis: mineralogical, organic and inorganic methods. (Springer Science \& Business Media, 2007).

50. Michelsen, T. C. \& Bragdon-Cook, K. Organic Carbon Normalization of Sediment Data. (Washington Department of Ecology, Olympia, WA, 1993).

51. McKeague, J. A. \& Day, J. H. Dithionite- and oxalate-extractable Fe and $\mathrm{Al}$ as aids in differentiating various classes of soils. Can. J. Soil Sci. 46, 13-22, doi: 10.4141/cjss66-003 (1966).

52. Gauch, H. G. Multivariate Analysis in Community Ecology. (Cambridge University Press, 1982).

53. Garćia, J. H. et al. Characterization and implication of potential fugitive dust sources in the Paso del Norte region. Sci. Total Environ. 325, 95-112, doi: 10.1016/j.scitotenv.2003.11.011 (2004).

54. Loska, K. \& Wiechuła, D. Application of principal component analysis for the estimation of source of heavy metal contamination in surface sediments from the Rybnik Reservoir. Chemosphere 51, 723-733, doi: 10.1016/S0045-6535(03)00187-5 (2003).

55. Kaiser, H. F. The application of electronic computers to factor analysis. Educ. Psychol. Meas. 20, 141-151, doi: 10.1177/001316446002000116 (1960)

\section{Acknowledgements}

We thank Dr. Jyh-Fu Lee for providing the beamtime of BL17C1 at the NSRRC. This study was funded by the research project supported by the Taiwan EPA and by the GREEnS project supported by Tunghai University in Taiwan. The views or opinions expressed in this article are those of the writers and should not be construed as 
opinions of the Taiwan EPA. Mention of trade names, vendor names, or commercial products does not constitute endorsement or recommendation by Taiwan EPA.

\section{Author Contributions}

L.-C.H., Y.-T.L. and Y.-M.T. designed the research and wrote this manuscript. The experiments were carried out by L.-C.H, C.-Y.H. and the statistical analysis was conducted by C.-Y.H., Y.-H.C., C.-F.C. and H.-W.C. The XAS analysis was performed and interpreted by Y.-T.C., H.-Y.T. and T.-Y.C. All authors contributed to the discussion of the results and edited the manuscript.

\section{Additional Information}

Supplementary information accompanies this paper at http://www.nature.com/srep

Competing financial interests: The authors declare no competing financial interests.

How to cite this article: Hsu, L.-C. et al. Accumulation of heavy metals and trace elements in fluvial sediments received effluents from traditional and semiconductor industries. Sci. Rep. 6, 34250; doi: 10.1038/srep34250 (2016).

(c) (i) This work is licensed under a Creative Commons Attribution 4.0 International License. The images or other third party material in this article are included in the article's Creative Commons license, unless indicated otherwise in the credit line; if the material is not included under the Creative Commons license, users will need to obtain permission from the license holder to reproduce the material. To view a copy of this license, visit http://creativecommons.org/licenses/by/4.0/

(c) The Author(s) 2016 